\title{
Thiemann disease and familial digital arthropathy - brachydactyly: two sides of the same coin?
}

\author{
Nadirah Damseh', Jennifer Stimec ${ }^{2}$, Alan O'Brien ${ }^{1}$, Christian Marshall $^{3}$, Ravi Savarirayann ${ }^{5}$, Ali Jawad ${ }^{6}$,
} Ronald Laxer ${ }^{4}$ and Peter Kannu ${ }^{1,7^{*}}$

\begin{abstract}
Background: Familial digital arthropathy-brachydactyly (FDAB) and Thiemann disease are non-inflammatory digital arthropathies with many phenotypic similarities. Thirty-three cases of Thiemann disease have been described so far (Mangat et al, Ann Rheum Dis 64:11-2, 2005; Ha et al, Thiemann's disease: a case Report, 2017) but no gene variants have been identified as causative to date. FDAB is reported in only a few patients and has been associated with three heterozygous missense variants in the Transient receptor potential vanilloid 4 (TRPV4) gene. We report a TRPV4 variant in a father and son referred with a diagnosis of Thiemann disease and compare the clinical and radiological features of Thiemann disease with Familial digital arthropathy-brachydactyly (FDAB). We hypothesize that these two entities may be one and the same.
\end{abstract}

Methods: We describe a father and son referred with a diagnosis of Thiemann disease who were subsequently identified with a heterozygous variant (c.809G > T) in TRPV4. The identical genetic variant was previously reported to cause FDAB. A PUBMED ${ }^{\circledR}$ database search was conducted to retrieve articles related to Thiemann disease and FDAB. We were able to review the clinical and radiological findings of nineteen individuals affected by Thiemann disease and compare them with three families affected by FDAB.

Results: Thiemann disease initially affects the proximal interphalangeal joints and primarily the middle phalangeal bases. In FDAB, the distal phalangeal joints are first affected with the middle phalangeal heads being the primary site of changes. Radial deviation has only been described in FDAB. Our analysis determined that 5 of 20 individuals affected by Thiemann disease have clinical and radiological findings that also fit well with FDAB.

Conclusion: FDAB and Thiemann disease are non-inflammatory digital arthropathies with phenotypic overlap. Although more extensive joint involvement, a distal hand joint preponderance and brachydactyly are expected in FDAB, there are striking clinical and radiological similarities between the two entities. Our analysis suggests that these two phenotypes may represent phenotypic variability of the same entity. Despite many attempts to identify other reported patients affected by Thiemann disease, we were not able to procure DNA from any of the cases to verify our findings. Genetic testing of an affected individual will be crucial in order to provide accurate reproductive genetic counselling about the autosomal dominant nature of this condition.

Keywords: TRPV4, Hand, Osteonecrosis, Osteoarthritis, Arthritis

\footnotetext{
* Correspondence: peter.kannu@sickkids.ca

'Division of Clinical and Metabolic Genetics, The Hospital for Sick Children

and University of Toronto, Toronto, ON M5G 1X8, Canada

${ }^{7}$ Developmental and Stem Cell Biology, The Hospital for Sick Children,

Toronto, ON M5G 1X8, Canada

Full list of author information is available at the end of the article
}

(c) The Author(s). 2019 Open Access This article is distributed under the terms of the Creative Commons Attribution 4.0 International License (http://creativecommons.org/licenses/by/4.0/), which permits unrestricted use, distribution, and

reproduction in any medium, provided you give appropriate credit to the original author(s) and the source, provide a link to the Creative Commons license, and indicate if changes were made. The Creative Commons Public Domain Dedication waiver (http://creativecommons.org/publicdomain/zero/1.0/) applies to the data made available in this article, unless otherwise stated. 


\section{Background}

Thiemann disease (OMIM 165700) is a rare deforming interphalangeal joint arthropathy of the fingers and toes. First described in 1909, Thiemann reported a 16-yearold male carpenter with painful and progressive proximal interphalangeal (PIP) joint enlargement. There was no family history suggestive of an inherited condition [1]. Subsequently, thirty-two cases of similar hand and foot epiphyseal abnormalities have been reported [2, 3]. Thiemann disease is believed to be autosomal dominant, demonstrating strong penetrance. No causative gene mutation has been identified to date $[4,5]$. The classical radiological features described include irregularity, flattening, fragmentation, and broadening of the basal phalangeal epiphyses, followed by joint space narrowing, premature physeal fusion, and phalangeal shortening [6]. The proposed clinical criterion by Handa et al., also include onset before the age of twenty-five, PIP joint swelling and the absence of elevated inflammatory markers [7].

Familial digital arthropathy-brachydactyly (FDAB, OMIM 606835) is an autosomal dominant digital arthropathy first described in 2002 [8]. To date, only two groups have reported affected patients [8-10]. FDAB presents in the first decade as a deforming arthropathy of the interphalangeal, metacarpophalangeal, and metatarsophalangeal joints. There is associated progressive brachydactyly of the middle and distal phalanges of the hands and feet. In 2011, Lamande et al., identified three different heterozygous missense variants in the Transient receptor potential vanilloid 4 (TRPV4) gene associated with FDAB. All three variants were shown to reduce TRPV4 channel activity $[9,11]$.

Here, we describe a father and son referred with a diagnosis of Thiemann disease whom were subsequently identified with a pathogenic TRPV4 variant. We review the literature on Thiemann disease and FDAB to show the phenotypic overlap. Based on our observations, we suggest that all individuals presenting with a Thiemann like phenotype undergo TRPV4 mutational analysis to clarify the genetic etiology of their condition.

\section{Patients and methods}

Patient (I) is a 15-year-old male who reported a two-year history of non-painful "crooked" fingers in the absence of trauma. His past medical history was significant for possible Raynaud phenomenon but otherwise noncontributory. On physical examination, his growth parameters were age appropriate. There was radial deviation of the second, third, fourth and fifth terminal phalanges bilaterally. There was asymmetrical involvement of the hands; the third phalanges were most affected and the right-hand digits were more severely affected than the left (Fig. 2, a1). His total hand length was $18 \mathrm{~cm}$ (50-
$75 \%)$ and middle finger length was $8 \mathrm{~cm}(75 \%)$. Other joints including those in the feet were normal on examination. His peripheral neurological examination was unremarkable.

Laboratory investigations (white blood cells, erythrocyte sedimentation rate, C-reactive protein, anti-nuclear antibodies, rheumatoid factor, anti-double stranded DNA antibodies, anti-SM antibodies, anti-RNP antibodies, anti-SS-A (RO) antibodies and anti-SS-B (La) antibody) were normal or negative.

Patient (II) is 50 years old and the father of Patient (I). $\mathrm{He}$ reported progressive finger joint deformities from the age of 10 . He was seen in the Orthopaedic clinic at The Hospital for Sick Children 15 years ago, and a diagnosis of Thiemann disease was considered. He has not required any treatment apart from analgesics for pain. He has also been diagnosed with gout, which occasionally affects his hands and feet. He has mild psoriasis. On examination, he is of above average stature. He had symmetrical hand changes. He had a fixed flexion deformity of the distal interphalangeal (DIP) joints, which were also prominent and radially deviated. His proximal interphalangeal joints were prominent and the range of movement limited. He also had prominent metatarsophalangeal joints without any limitation to active movement. No other joints were clinically involved. His peripheral neurological examination was unremarkable. There were no deficits in power, sensation or position sense.

An autosomal dominant inheritance was suspected based on the observation of male to male transmission. A Next Generation skeletal dysplasia gene panel (The Hospital for Sick Children, Toronto) identified a heterozygous pathogenic variant $(\mathrm{c} .809 \mathrm{G}>\mathrm{T})$ in the TRPV4 gene in patient (I) and patient (II). This variant has previously been reported in a patient with familial digital arthropathy-brachydactyly [9].

\section{Literature review}

A PUBMED ${ }^{\circ}$ database search was conducted in an iterative manner during September-November 2016 to retrieve articles related to Thiemann disease. Search terms included "Thiemann" "Thiemanns" and "Familial digital arthropathy". A relatively small number of articles exist on the topic. The reference list of each article was reviewed in detail to find additional articles.

Thirty-five articles published between 1954 and 2017 were found, written in different languages (English $(n=$ 19), French $(n=5)$, Deutsch $(n=4)$, Polish $(n=1)$, Romanian $(\mathrm{n}=1)$, Italian $(\mathrm{n}=1)$, undetermined language $(n=2))$. We excluded documents that were not in English or French. A search using the University of Toronto Libraries online database identified the records of eighteen English and two French articles about Thiemann 
disease and three English articles about FDAB. These articles were read in full text and the relevant findings were summarized in Table 1 .

\section{Results}

To date, three families affected by FDAB have been reported and 33 cases of Thiemann disease identified. We were able to review 20 cases of Thiemann disease [see Additional file 1: Table S1]. In 5/20 Thiemann cases, the clinical and radiological descriptions fit well with FDAB ((Miric et al. (1971) (I and II), Ernest et al. (1954), Van der Laan et al. (1986), and Jawdat et al. (2005)) [2, 1214]. The clinical and radiological features of Thiemann disease and FDAB are summarized in Table 1.

\section{Clinical findings}

The onset of disease in patients with Thiemann disease was in the second decade of life in $65 \%$ of patients $(13 / 20)$, median age was 24 years (range 8 years to 40 years). There were three individuals described with disease onset before the first decade; in two of these individuals, both DIP and PIP joints were affected at the time of initial presentation. Although the condition is described as 'mild' in many of the younger reported patients, this was not a consistent observation. For example, the cases described by Molloy et al. (1978) and Gewanter et al. (1985) presented with a severe joint phenotype at the age of 10 years and 12 years respectively $[15,16]$.

Joint involvement was symmetrical in $85 \%(17 / 20)$. Joint pain exacerbated by hand use or cold exposure was reported in 68\% (13/20). Soft tissue swelling around the PIP joints, and less commonly the DIP joint, was described in all cases. Other than the hands and feet, no individuals reported any other large joint involvement or features of a systemic illness. While radial deviation of the interphalangeal joints was common in the FDAB cases, this was not reported in Thiemann disease. Few patients affected by Thiemann disease developed ulnar deviation of the hand joints (Miric et al. (1971), Molloy et al. (1978) see Fig. 1-f, Kotevoglu-Senerdem et al. (2003) see Fig. 1-d) [12, 15, 17].

Table 1 Comparison of Thiemann disease and FDAB

\begin{tabular}{|c|c|c|}
\hline & Thiemann disease & $\begin{array}{l}\text { Familial Digital Arthropathy and Brachydactyly } \\
\text { (FDAB) }\end{array}$ \\
\hline Gender & $\begin{array}{l}\text { M-F ratio is } 1: 1.1 \\
\text { ( } 9 \text { males, } 10 \text { females, } 17 \text { different families) }\end{array}$ & $\begin{array}{l}\text { M-F ratio is } 1: 1.1 \\
\text { (12 males, } 13 \text { females, } 4 \text { different families) }\end{array}$ \\
\hline Age of onset & 8 years -40 years (median age $=24$ years) & First decade, earliest reported age was 10 years. \\
\hline $\begin{array}{l}\text { Pattern of inheritance /genetic } \\
\text { etiology }\end{array}$ & Autosomal dominant/ unknown & Autosomal dominant/TRPV4 variants \\
\hline \multicolumn{3}{|l|}{ Clinical features } \\
\hline Pain & 73\% (14/19), usually mild. & Prominent feature \\
\hline Swelling & $75 \%(15 / 20)$ & Prominent feature \\
\hline Joint movement limitation & $73 \%(14 / 20)$ & Present \\
\hline Symmetrical & $85 \%(17 / 20)$ & Prominent feature \\
\hline \multicolumn{3}{|l|}{ Radiological features } \\
\hline Affected hand joints & $\begin{array}{l}95 \%(19 / 20): \text { PIPs are more severely affected than } \\
\text { DIPs } \\
\text { o PIPS } 95 \%(19 / 20) \\
\text { o DIPS } 40 \%(8 / 20) \\
\text { O MCPs } 20 \%(4 / 20)\end{array}$ & $\begin{array}{l}\text { Constant involvement of PIPS, DIPs and MCPs. } \\
\text { (DIPs were more severely affected than PIPS) }\end{array}$ \\
\hline Affected feet joints & $20 \%(4 / 20)-$ MTPs & By adulthood, all MTPs are affected \\
\hline Flattening & $35 \%(7 / 20)$ & Prominent feature \\
\hline Irregularities & $45 \%(9 / 20)$ & Prominent feature \\
\hline Short phalanges & $25 \%(5 / 20)$ & Prominent feature (progressive) \\
\hline Broadening & $15 \%(3 / 20)$ & Present \\
\hline Joint space reduction & $\begin{array}{l}40 \%(8 / 20) \\
\text { o PIPs }(8 / 20) \\
\text { o DIPs }(3 / 20)\end{array}$ & Present (in adulthood) \\
\hline Subchondral cysts & $5 \%(1 / 20)$ & Present \\
\hline Fragmentation & $35 \%(7 / 20)$ & Not reported \\
\hline Lateral deviation & $5 \%(1 / 20)-$ ulnar & Prominent feature (Radial>ulnar) \\
\hline
\end{tabular}

$M$ male, $F$ female, PIPs proximal interphalangeal joints, DIPs distal interphalangeal joints, MCPs metacarpophalangeal joints, MTPs metatarsophalangeal joint 

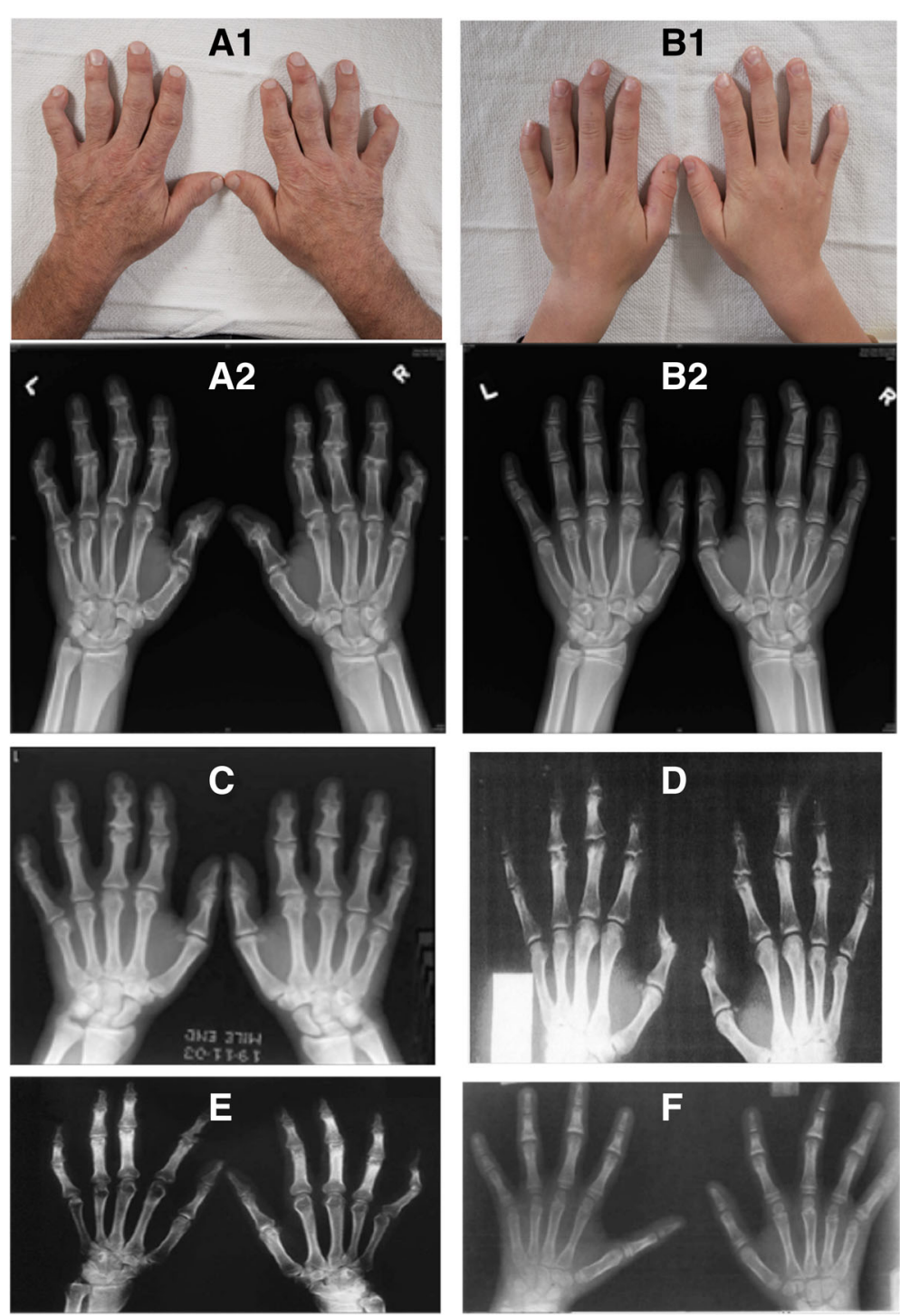

Fig. 1 (a1, a2) patient (II). Multiple bony abnormalities present, particularly involving the heads of the middle phalanges characterized by irregularity, flattening, and radial angulation. Bilateral symmetric marked joint space loss of the 2nd-5th DIP and PIP joints, 1st IP joints, left 5th MCP and right 2nd MCP joints. Osteophyte formation in a similar distribution with a subchondral cyst in the left 3rd DIP. Shortening of the middle phalanges, worst at the second and fifth digit is seen. $(\mathbf{b} 1, \mathbf{b} 2)$ patient (I). Short and broad middle phalanges bilaterally, worst at the 2 nd and 5 th fingers. Irregularity and sloping of the 2 nd -5 th middle phalangeal heads with resultant radial deviation. No secondary degenerative changes. (c) 19-year-old man reported by Jawad et al. with Thiemann disease. There is flattening and irregularity of the phalangeal epiphyses and broadening of the PIP and DIP joints. There are signs of secondary osteoarthritis including joint space loss and osteophyte formation. Mild shortening of 2nd-5th middle and distal phalanges. (d) 17-year-old boy reported by Nurdan Kotevoglu-Senerdem et al. with Thiemann disease. There is irregularity, fragmentation and flattening of the 2nd-4th PIP and DIP joints. (e) 25-year-old women reported by Seçkin et al. with Thiemann disease. Note irregularity and flattening of the epiphyses and flexion deformity of both fifth finger PIP joints. There is thickening at the base of all proximal phalanxes and all middle phalanxes were broad. There is narrowing at the third and fourth DIP and fifth PIP joints of both hands. (f) Thiemann disease case report of a 10-year-old female by Molloy et al. There are dense sclerotic distal phalangeal epiphyses (ivory epiphyses). There is broadening and irregularity of the 2-5th middle phalangeal bases with premature physeal fusion and relative shortening. Mild ulnar deviation of the right third PIP joint. Note: permissions were obtained from the copyright holder to reuse the images $c, d, e$ and $f$

\section{Radiological findings}

Common radiological findings reported in Thiemann disease include proximal and distal joint irregularity, subchondral cysts, joint space reduction, erosions, flattening of the distal phalangeal base, and a slight reduction in the middle and distal phalangeal lengths. However, these features were also noted in FDAB (Fig. 1). Thiemann disease initially affects the proximal interphalangeal joints and primarily the middle phalangeal bases, unlike FDAB where distal phalangeal joints are 
first affected with the heads of the middle phalanges the primary site of change.

Almost always, both interphalangeal joints of the hand (PIP > DIP) were affected in Thiemann disease while the feet were affected in 20\% (4/20) of individuals. Shortening of the hand phalanges was documented in 25\% (5/ 20) of individuals. The thumb was typically spared. Shortening and broadening of the phalangeal and metacarpal bones was found in 30\% (6/20) of individuals. In three individuals, carpal bone abnormalities were described. In the feet, the metatarsophalangeal joints were typically affected but interphalangeal joint involvement less common.

\section{Discussion}

Thiemann disease represents a progressive hand and foot arthropathy with variable expressivity and an autosomal dominant pattern of inheritance [1]. Curiously, a few mildly affected individuals who made a complete recovery with no lasting signs of arthritis have been described $[14,15]$. Thiemann disease may present as early as age 4 years but is more commonly diagnosed in the early teen years [6]. In a typical case, an affected individual reports relatively painless swelling of the proximal interphalangeal joints or an inability to use the digit [3, $6,11,14]$. Proximal interphalangeal joint involvement, and to a lesser extent, involvement of the first metatarsophalangeal and metacarpophalangeal joints is well described [1, 3, 10-13]. Mild shortening of the phalanges is also commonly reported [4]. On the other hand, FDAB is a more aggressive arthropathy developing in the first decade of life. Unlike Thiemann disease, the interphalangeal, metacarpophalangeal and metatarsophalangeal joints are all typically affected and joint pain is a significant feature. Similar to Thiemann disease, the thumb is frequently spared and the hands more involved than the feet. In both entities, the remainder of the skeleton is clinically and radiographically unaffected [9]. We found the formulated radiological criteria suggested by Melo-Gomes et al. and the revised tentative radiological criteria by Van der Laan et al. for Thiemann disease no more sensitive in eliminating the possibility of FDAB.

The underlying pathological processes in Thiemann disease and FDAB are believed to be different. Thiemann disease is classified as a juvenile osteochondritis similar to Legg-Calvé-Perthes disease and Scheuermann disease [12]. Pathological analysis is only available from a single case where the finger joint showed varying degrees of epiphyseal cartilage necrosis without an inflammatory response [5]. FDAB is hypothesized to result from an arrest of bone growth or bone resorption at the joint subchondral region. Since the earliest observed changes are the deformed and flattened proximal articular surfaces with intact distal articular surfaces and joint spaces, Amor et al. 2011 hypothesized that brachydactyly is secondary to the joint disease in FDAB [8]. We note however, the TRPV4 mutation described in this report, which has previously been described to cause FDAB, was not associated with brachydactyly. We also believe the epiphyseal changes affecting the middle phalanges of patient (II) could represent avascular necrosis of the radial aspect of the phalangeal condyles. Upon collapse of the condyles, the distal interphalangeal joints would manifest a radial deviation.

Based on the data presented here, we believe that localization of the initial most affected joint helps in discriminating between the two entities. In Thiemann disease, the proximal interphalangeal joints are first affected. FDAB starts in the most distal hand joints, progressively involving the proximal interphalangeal joints and eventually, the metaphalangeal and metatarsophalangeal joints. As the disease progresses, the distal interphalangeal joints develop radiological deformities and restricted movement compared to the proximal interphalangeal joints. Radial deviation of the phalanges is documented in FDAB, but has not been reported in Thiemann disease [12]. More joints are affected in FDAB and pain seems to be a more striking component of the phenotype.

Familial Thiemann disease shows an equal sex distribution, while sporadic cases demonstrate a two-third's male predominance [6]. No specific radiological differences exist between these two groups of patients and the genetic cause of Thiemann disease is thus far unknown. In the family we describe, a TRPV4 variant previously reported to cause FDAB was identified. To date, only three different TRPV4 variant causing FDAB has been reported. TRPV4 forms a Ca2 +-permeable cation channel that is stimulated by heat and mechanical stress. All reported FDAB mutations to date are fully penetrant and affect the third finger of the TRPV4 intracellular ankyrin-repeat domain resulting in a reduction of channel activity and impairment of cartilage hemostasis [9, 11]. Gain-of-function TRPV4 variants are associated with other phenotypes varying from severe skeletal dysplasias to peripheral neuropathies (Fig. 2). Recently, a novel gain of function TRPV4 variant was associated with inherited osteonecrosis of the femoral head [18].

\section{Conclusion}

FDAB and Thiemann disease are non-inflammatory digital arthropathies presenting in the first two decades of life with many phenotypic similarities. Neither condition seems to affect other joints. TRPV4 variants cause FDAB while the familial nature of Thiemann disease is consistent with a genetic etiology. Our report describing a TRPV4 variant in a father and son referred with a diagnosis of Thiemann disease suggests the historical accounts of these two different phenotypes may be 


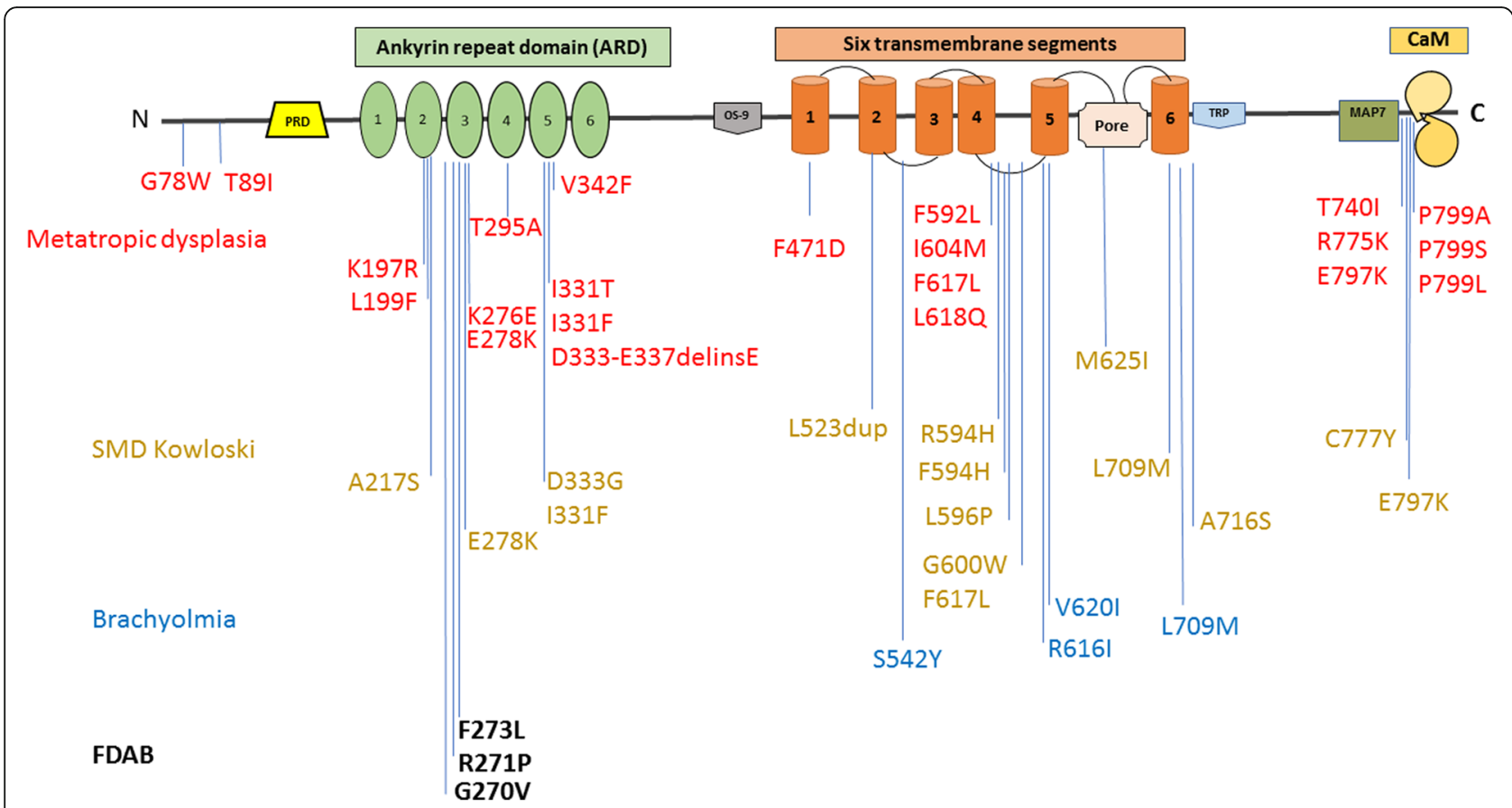

Fig. 2 Protein sequence and disease-causing mutations in TRPV4. PRD, protein rich domain. CaM, calmodulin. MAP7, microtubule-associated protein 7

inaccurate in some instances, and that they may be different manifestations of the same disease. Although more extensive joint involvement, a distal hand joint preponderance and brachydactyly are expected in FDAB, there are striking radiological similarities between the two entities. Despite many attempts to identify other affected patients, we were unfortunately unable to procure DNA from any of the previously reported cases to verify our findings. Genetic testing of an affected individual will be crucial in order to provide accurate reproductive genetic counselling about the autosomal dominant nature of this condition.

\section{Additional file}

Additional file 1: Table S1. Clinical and radiological manifestations of Thiemann's disease in all reviewed cases. (DOCX $54 \mathrm{~kb}$ )

\section{Abbreviations}

DIP: Distal interphalangeal; FDAB: Familial digital arthropathy-brachydactyly; PIP: Proximal interphalangeal; TRPV4: Transient receptor potential vanilloid 4

\section{Acknowledgments}

Not applicable.

\section{Authors' contributions}

We declare that this work was done by the authors named in this article. All authors contributed to the manuscript revision and approval of the final version. ND collected data from English articles and wrote first draft. AO collected data from the French articles included. JS reviewed and interpreted the radiological images. CM reviewed the molecular genetic data.

\section{Funding}

SickKids Hospital grant funding.
Availability of data and materials

All articles included in the review are listed in the references. Articles were identified in Pubmed database and access to full text is dependent on journal and institutional constraints.

Ethics approval and consent to participate

No ethical approval is required. Permissions to reuse the radiological images $(c, d, e, f)$ in (Fig. 1) were obtained.

\section{Consent for publication}

Consent to participate was obtained from the two patients reported.

\section{Competing interests}

The authors declare that they have no competing interests, and all authors should confirm its accuracy.

\section{Author details}

'Division of Clinical and Metabolic Genetics, The Hospital for Sick Children and University of Toronto, Toronto, ON M5G 1X8, Canada. ${ }^{2}$ Department of Diagnostic Imaging, The Hospital for Sick Children University of Toronto, Toronto, ON, Canada. ${ }^{3}$ Department of Paediatric Laboratory Medicine and Laboratory Medicine and Pathobiology, The Hospital for Sick Children and University of Toronto, Toronto, ON M5G 1X8, Canada. ${ }^{4}$ Division of Rheumatology, Department of Paediatrics and Medicine, The Hospital for Sick Children, University of Toronto, Toronto, ON, Canada. ${ }^{5}$ Victorian Clinical Genetics Service, Murdoch Childrens Research Institute, The University of Melbourne, Melbourne, Australia. ${ }^{6}$ Department of Rheumatology The Royal London Hospital, The University of London, E1 4DG, London, UK.

${ }^{7}$ Developmental and Stem Cell Biology, The Hospital for Sick Children,

Toronto, ON M5G 1X8, Canada.

Received: 30 November 2018 Accepted: 12 June 2019

Published online: 27 June 2019

\section{References}

1. Thiemann H. Juvenile Epiphysenstorungen. Fortschr Geb Rontgenstr. 1909: 14:79-87. 
2. Mangat $P$, Jawad AS. Case number 32: Thiemann's disease. Ann Rheum Dis. 2005;64(1):11-2.

3. Ha Kim Y, Lee J. Thiemann's disease: a case Report, vol. 273; 2017.

4. Rubinstein HM. Thiemann's disease. A brief reminder. Arthritis Rheum. 1975; 18(4):357-60.

5. Allison AC, Blumberg BS. Familial osteoarthropathy of the fingers. The Journal of bone and joint surgery British volume. 1958;40-b(3):538-45.

6. Melo-Gomes JA, Melo-Gomes E, Viana-Queiros M. Thiemann's disease. J Rheumatol. 1981;8(3):462-7.

7. Handa R, Aggarwal P, Wali JP. A young boy with deforming arthropathy Ann Rheum Dis. 1998:57(2):79-80.

8. Amor DJ, Tudball C, Gardner RJ, Lamande SR, Bateman JF, Savarirayan R. Familial digital arthropathy-brachydactyly. Am J Med Genet. 2002;108(3): $235-40$

9. Lamande SR, Yuan Y, Gresshoff IL, Rowley L, Belluoccio D, Kaluarachchi K, et al. Mutations in TRPV4 cause an inherited arthropathy of hands and feet. Nat Genet. 2011:43(11):1142-6.

10. Horta-Baas G, Vergara-Sanchez I, Romero-Figueroa MDS. Familial digital arthropathy-brachydactyly: an infrequent cause of joint deformity in adolescents. Medicina clinica. 2017;149(11):512-3.

11. Nilius B, Voets T. The puzzle of TRPV4 channelopathies. EMBO Rep. 2013; 14(2):152-63.

12. Miric $V$, Jankulov D, Tomasevic M. 2 cases of Thiemann's diseaseRevue $d u$ rhumatisme et des maladies osteo-articulaires. 1971;28(10):653-4.

13. van der Laan JG, Thijn CJ. Ivory and dense epiphyses of the hand: Thiemann disease in three sisters. Skelet Radiol. 1986;15(2):117-22.

14. Shaw EW. Avascular necrosis of the phalanges of the hands (Thiemann's disease). J Am Med Assoc. 1954;156(7):711-3.

15. Molloy MG, Hamilton EB. Thiemann's disease. Rheumatology and rehabilitation. 1978;17(3):179-80.

16. Gewanter H, Baum J. Thiemann's disease. J Rheumatol. 1985;12(1):150-3.

17. Kotevoglu-Senerdem N, Toygar B, Toygar B. Thiemann disease. Journal of clinical rheumatology : practical reports on rheumatic \& musculoskeletal diseases. 2003;9(6):359-61.

18. Mah W, Sonkusare SK, Wang T, Azeddine B, Pupavac M, Carrot-Zhang J, et al. Gain-of-function mutation in TRPV4 identified in patients with osteonecrosis of the femoral head. J Med Genet. 2016:53(10):705-9.

\section{Publisher's Note}

Springer Nature remains neutral with regard to jurisdictional claims in published maps and institutional affiliations.

Ready to submit your research? Choose BMC and benefit from:

- fast, convenient online submission

- thorough peer review by experienced researchers in your field

- rapid publication on acceptance

- support for research data, including large and complex data types

- gold Open Access which fosters wider collaboration and increased citations

- maximum visibility for your research: over $100 \mathrm{M}$ website views per year

At $\mathrm{BMC}$, research is always in progress.

Learn more biomedcentral.com/submissions 